\title{
Impact of flex power on GPS Block IIF differential code biases
}

\author{
Özge Gizem Esenbuğa ${ }^{1}$ • $\cdot$ André Hauschild ${ }^{1}$
}

Received: 24 March 2020 / Accepted: 4 June 2020 / Published online: 8 July 2020

(c) The Author(s) 2020

\begin{abstract}
GPS Block IIF satellites are able to redistribute the transmit power between the signal components. This ability is called flex power, and it has been developed as a remedy against jamming. Since it is operationally not possible to increase the transmit power for all signal components simultaneously, a redistribution between them is necessary under certain operational situations. Flex power has been active on Block IIF satellites since January 2017 over a specific regional area and has an impact on differential code bias estimation as well as the signal-to-noise density ratio. A network of the International GNSS Service stations containing only Septentrio PolaRx5 and PolaRx5TR receivers between August 1 and November 21, 2019 has been used for differential code bias estimation using GPS L1 C/A, L1 P(Y), L2 P(Y), and L2C signals with and without consideration of the flex power in the estimation process for Block IIF satellites. The estimation results are compared with the German Aerospace Center as well as the Chinese Academy of Sciences DCB products to validate the results.
\end{abstract}

Keywords Differential Code Biases · Flex Power · GPS Block IIF

\section{Introduction}

The Block IIF satellites are the fourth generation of the GPS satellites. These satellites provide the new L5 signal in addition to the legacy GPS L1 C/A code, L1/L2 P(Y) code signals, the civil L2C signal on L2, and the military M code on L1/L2. The motivation for launching the Block IIF satellites was replacing failed satellites using the so-called "launch on need" approach (Fisher and Ghassemi 1999). The first Block IIF satellite was launched in May 2010 (Federal Radionavigation Plan 2019). There are in total 12 different Block IIF satellites in operation.

All GPS satellites normally transmit their signal with constant total power and constant power ratios between the different signal components. Nevertheless, Block IIR-M and Block IIF satellites are able to redistribute the transmit power between L1 and L2 signals individually (Rajan and Tracy 2002). Owing to the adjustable power output capability, the individual signal components of Block IIR-M and

Özge Gizem Esenbuğa

oezge.esenbuga@dlr.de

André Hauschild

andre.hauschild@dlr.de

1 Deutsches Zentrum für Luft- und Raumfahrt, German Space Operations Center, 82234 Wessling, Germany
Block IIF satellites can exceed their pre-defined maximum value. However, this value is not expected to exceed -150 dBW under certain operational situations (IS-GPS-200K 2019). The ability to redistribute the transmit power is called flex power. There are different kinds of flex power modes that have been studied so far (Steigenberger et al. 2018). The flex power mode discussed here is the one that is empowered since January 2017 on the Block IIF satellites, and its signature is a power increase by $2.5 \mathrm{~dB}-\mathrm{Hz}$ of the $\mathrm{L} 1 \mathrm{C} / \mathrm{A}$ and $\mathrm{P}(\mathrm{Y})$ signals over an area centered at the geographic location $41^{\circ} \mathrm{E}$ and $37^{\circ} \mathrm{N}$. It has been shown in the previous research that flex power has an impact on pseudorange biases (Steigenberger et al. 2018). This flex power mode is enabled for almost the entire eastern hemisphere; therefore, it is important to analyze its impact on the biases.

The pseudorange biases occur due to the differences in the chip shape distortions among the GNSS satellites. This bias might be slightly different when different receivers are used (Hauschild and Montenbruck 2016). The pseudorange biases are systematic offsets in the group delay of the signal generation and processing chain, and they depend on the frequency of the transmitted signal as well as the employed phase modulation (Montenbruck et al. 2014). In case two different GNSS code signals on the same or different frequencies are used together, their pseudorange biases are not the same causing a differential code bias (DCB) (Steigenberger 
et al. 2018). Studies have concluded that DCBs are important to consider when estimating the total electron content using GPS data. Therefore, estimation or calibration of them is necessary (Sardón and Zarraoa 1997). In addition, DCBs are necessary for precise point positioning (PPP) with ambiguity resolution applications (Geng et al. 2011).

We analyze the impact of the flex power on DCB estimates. In this context, the DCBs are estimated with and without considering the flex power between August 1 and November 21, 2019. To decrease the effects of different front-end and correlator settings on the estimated DCBs, a global network of exclusively Septentrio PolaRx5 and PolaRx5TR receivers is used. The estimated results are compared with other agencies for the validation.

\section{Flex power}

Finding an improved and effective remedy against jamming has received great attention in the design of modernized GPS satellites. This started with the modernization of the Block IIR satellites (Block IIR-M) and continued with the next generation the Block IIF GPS satellites (Fisher and Ghassemi 1999; Rajan and Tracy 2002). To improve the concept against jamming, new transmitters are used that allow the adjustment of the radio frequency power output via a command from the Control Segment (CS) (Rajan and Tracy 2002). This redistribution is between individual signals of the L1 and L2 frequency bands to remedy against jamming. This is called flex power. It changes the modulation of the GPS signals and is visible for most of the Block IIF satellites as modified biases in pseudorange and carrier phase measurements (Steigenberger et al. 2018).
The flex power has an impact on the signal-to-noise density ratio $\left(\mathrm{C} / \mathrm{N}_{0}\right)$ measured by the receiver as well as the estimation of the satellite DCBs (Steigenberger et al. 2018). For the detection of flex power activation and deactivation times, time-differences of $\mathrm{C} / \mathrm{N}_{0}$ observations are analyzed to identify step-wise changes that are simultaneously observed by several geodetic receivers and exceed a certain threshold for the $\mathrm{C} / \mathrm{N}_{0}$ difference. It has also been seen that the activation of flex power affects the DCBs on those signals, which are subject to the power changes (Steigenberger et al. 2018). The impact is analyzed by estimating additional DCB values during flex power activation times and comparing them to the normal DCBs without flex power.

\section{Receiver network for DCB estimation}

DCBs are estimated using a globally distributed network of Septentrio PolaRx5 and PolaRx5TR receivers. The reason for using one receiver type is to eliminate the effect of different front-end bandwidths and correlator designs as much as possible. As both receivers correspond to the same series, it is safe to assume that they have identical correlators. In addition, under the assumption that the IGS network uses the standard settings for each receiver, it can be assumed that multipath mitigation is not activated. Hence, the globally distributed network consists of homogenous receivers and receiver settings. Figure 1 depicts the distribution of the Septentrio network. It includes 65 globally distributed IGS stations. The activation area of the flex power is shown with a yellow line. Satellites at orbital positions with a subsatellite point to the north of that line have flex power activated, indicated by colored ground tracks of the Block IIF
Fig. 1 Network of 65 Septentrio PolaRx5 and PolaRx5TR receivers and the activation area of the flex power (yellow line) and the ground tracks of GPS Block IIF satellites on August 1, 2019. The colored lines indicate the satellite's ground track and the colored dots mark the activation or deactivation of the flex power for individual satellites. The center point of the activation region is marked with a yellow cross

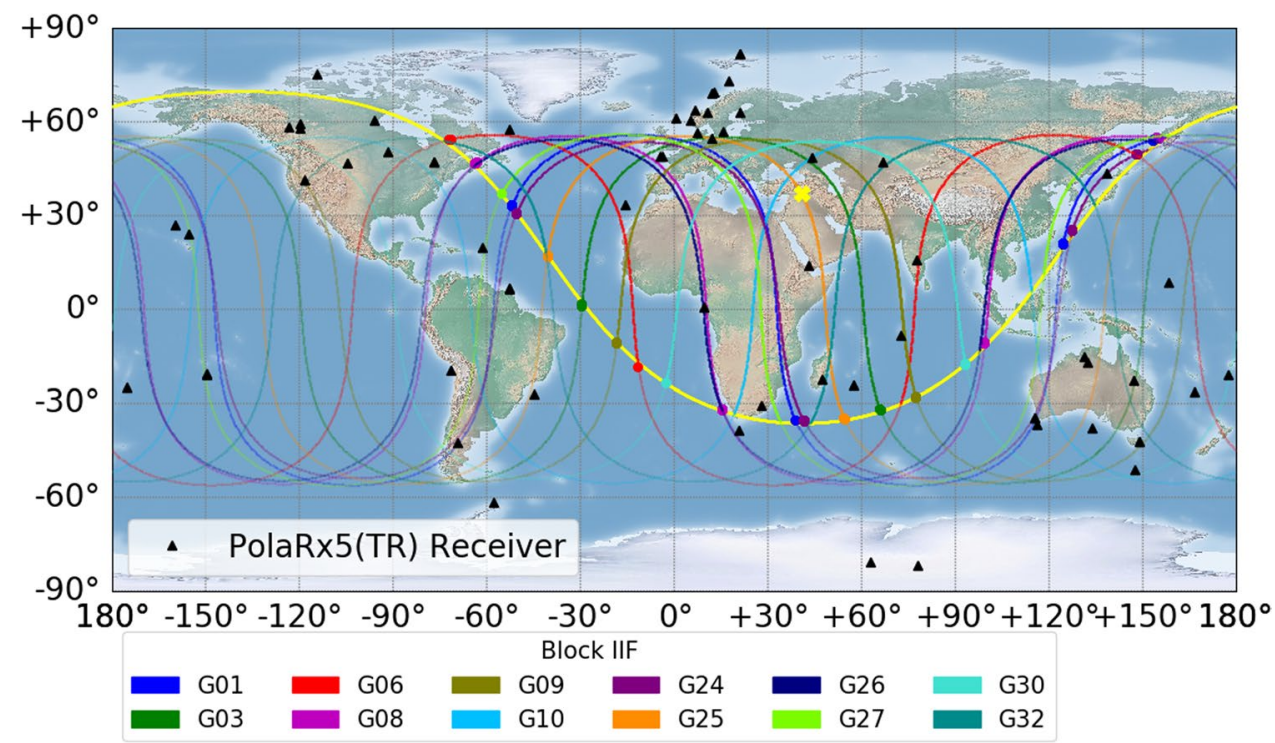


satellites. The colored dots are the positions at activation or deactivation of the flex power of the individual Block IIF satellites. The yellow cross indicates the center point of the activation region. The center point of the flex power and its activation or deactivation is determined by fitting the border of a visibility cone to step-wise changes occurring in $\mathrm{C} / \mathrm{N}_{0}$ in the IGS network.

We estimate three different DCBs for the GPS constellation. The information about the estimated DCBs is summarized in Table 1. The observation codes follow the RINEX3 naming convention for different observation types. On the $\mathrm{L} 1$ band, the $\mathrm{C} 1 \mathrm{C}$ and $\mathrm{C} 1 \mathrm{~W}$ observations are used, which are provided, respectively, by the C/A code and semi-codeless tracking of legacy P-code signals (Anti-spoofing on). For the $\mathrm{L} 2$ band, the $\mathrm{C} 2 \mathrm{~W}$ and $\mathrm{C} 2 \mathrm{~L}$ observations are used for DCB estimation. These observations are provided by the semi-codeless tracking of legacy P-code signals (Antispoofing on) and L2C code, respectively (IGS RINEX WG and RTCM-SC104 2018). The DCBs between signals on the same frequency are called intra-frequency DCBs. DCBs for signals on different frequencies are called inter-frequency DCBs. To isolate the effect of the flex power, the $\mathrm{C} 1 \mathrm{C}-\mathrm{C} 1 \mathrm{~W}$ intra-frequency DCB is estimated. In this way, the effect of the ionosphere is eliminated, because both signals have the same frequency. To be able to estimate the inter-frequency DCB and investigate the effect of flex power on it, the ionospheric delay must be estimated. This is done for the $\mathrm{C} 1 \mathrm{C}-\mathrm{C} 2 \mathrm{~W}$ DCB. Finally, to verify that the flex power impacts the DCBs only on the L1 band, and the L2 $\mathrm{C} 2 \mathrm{~W}-\mathrm{C} 2 \mathrm{~L}$ intra-frequency DCBs are additionally estimated.

\section{DCB estimation}

To estimate inter- and intra-frequency DCBs listed in Table 1, the pseudorange observations are used. Ignoring the antenna phase center variations, the pseudorange observations from satellite $s$ to receiver $r$ on frequency $f_{i}$ are modeled as:

$$
\begin{aligned}
P_{r, i}^{s}\left(t_{n}\right) & =\rho_{r}^{s}\left(t_{n}\right)+c\left(\delta \tau_{r}\left(t_{n}\right)-\delta \tau^{s}\left(t_{n}-\Delta t_{n}\right)\right) \\
& +m_{T}\left(E_{r}^{s}\left(t_{n}\right)\right) T_{z, r}\left(t_{n}\right)+q_{1, i}^{2} I_{r}^{s}\left(t_{n}\right)+b_{i}^{s}+b_{r, i}+\eta_{r, i}^{s}\left(t_{n}\right)
\end{aligned}
$$

Table 1 Frequency and RINEX3 observation codes of estimated DCBs

\begin{tabular}{lll}
\hline Frequency & Observation codes & DCB type \\
\hline L1 & $\mathrm{C} 1 \mathrm{C}-\mathrm{C} 1 \mathrm{~W}$ & Intra-frequency \\
$\mathrm{L} 1-\mathrm{L} 2$ & $\mathrm{C} 1 \mathrm{C}-\mathrm{C} 2 \mathrm{~W}$ & Inter-frequency \\
$\mathrm{L} 2$ & $\mathrm{C} 2 \mathrm{~W}-\mathrm{C} 2 \mathrm{~L}$ & Intra-frequency \\
\hline
\end{tabular}

with the reception time of the signal $t_{n}$, the travel time of the signal $\Delta t_{n}$, the geometric range $\rho_{r}^{s}$, the speed of the light in vacuum $c$, the clock offset of the receiver $\delta \tau_{r}$, the clock offset of the satellite $\delta \tau^{s}$, the mapping function $m_{T}$ for the elevation $E_{r}^{s}$, tropospheric zenith delay $T_{z, r}$, ionospheric delay $I_{r}^{s}$, the square of the ratio of L1 frequency $f_{1}$, and the observation frequency $f_{i}$. We further have $q_{1, i}^{2}=f_{1}^{2} / f_{i}^{2}$, the satellite code bias $b_{i}^{s}$, receiver code bias $b_{r, i}$, and noise and multipath errors $\eta_{r, i}^{s}$

Note that here the biases are absolute pseudorange biases. To estimate differential biases, a geometry-free linear combination of two pseudorange measurements of the same satellite is formed. In this way, the geometry-dependent, as well as frequency-independent terms in (1) drop out. After substituting $q_{1, i}^{2}=f_{1}^{2} / f_{i}^{2}=1$ as well as $q_{1,2}^{2}=f_{1}^{2} / f_{2}^{2}$ and rearranging the equation, the remaining terms for frequencies $f_{1}$ and $f_{2}$ are:

$$
\begin{aligned}
& P_{r, 2}^{s}\left(t_{n}\right)-P_{r, 1}^{s}\left(t_{n}\right)=\left(q_{1,2}^{2}-1\right) I_{r}^{s}\left(t_{n}\right) \\
& \quad+\left(b_{2}^{s}-b_{1}^{s}\right)+\left(b_{r, 2}-b_{r, 1}\right)+\left(\eta_{r, 2}^{s}\left(t_{n}\right)-\eta_{r, 1}^{s}\left(t_{n}\right)\right)
\end{aligned}
$$

The ionospheric delay in (2) can be related to the Slant Total Electron Content (STEC) using $I_{r}^{s}\left(t_{n}\right)=\frac{40.31}{f_{1}^{2}}$ STEC (Hauschild 2017). In addition, the satellite and receiver biases can be merged into satellite and receiver DCBs respectively. Furthermore, the noise terms can also be represented as one merged term, giving:

$P_{r, 2}^{s}\left(t_{n}\right)-P_{r, 1}^{s}\left(t_{n}\right)=40.31\left(\frac{1}{f_{2}^{2}}-\frac{1}{f_{1}^{2}}\right) \operatorname{STEC}^{s}\left(t_{n}\right)+b_{21}^{s}+b_{r, 21}+\eta_{r, 21}^{s}\left(t_{n}\right)$

Separating the receiver DCBs, $b_{r, 21}$, and satellite DCBs, $b_{21}^{s}$, in (3) is possible under the assumption that the receiver and transmitter chain generate biases that do not depend on each other and are separable. Although this assumption is not true in reality, it is a standard assumption in the DCB estimations. However, in this case, the equation system is rank deficient; therefore, a zero-sum condition for all satellites is applied to overcome this problem. Another possible remedy could be fixing a single receiver DCB in the network. In this study, the zero-sum condition is applied, as it is commonly used within the International GNSS Service (IGS) (Montenbruck et al. 2014). The zero-sum condition is formulated as:

$\sum_{s=0}^{k} b_{21}^{s}=0$

which means that the sum of all satellite DCBs per constellation is zero.

STEC in (3) can be represented as a product of a mapping function $m\left(E_{\mathrm{r}}^{s}\left(t_{n}\right)\right)$ with the corresponding elevation $E_{r}^{s}$ from 
receiver $r$ to satellite $s$ and Vertical Total Electron Content (VTEC) at the reception time of the signal $t_{n}$. Additionally, the first-order gradient contributions of the ionospheric path delay can also be considered for more precise modeling. The equation is written as:

$\operatorname{STEC}^{s}\left(t_{n}\right)=m\left(E_{r}^{s}\left(t_{n}\right)\right)\left(\operatorname{VTEC}\left(t_{n}\right)\right.$

$\left.+\nabla_{\phi}\left(t_{n}\right)\left(\phi_{g, p}\left(t_{n}\right)-\phi_{g, 0}\right)+\nabla_{\lambda}\left(t_{n}\right)\left(\lambda_{g, p}\left(t_{n}\right)-\lambda_{g, 0}\right)\right)$

where $\nabla_{\phi}$ and $\nabla_{\lambda}$ denote latitudinal and longitudinal vertical ionospheric delay gradients in meter/degree, respectively. $\phi_{g, p}$ and $\lambda_{g, p}$ are the geographic latitude and longitude of the piercing point in degree. $\phi_{g, 0}$ and $\lambda_{g, 0}$ represent the geographic latitude and longitude of the station in degree.

The mapping function in (5) is an approximation to model the ionosphere. The simplest approach, Single Layer Model (SLM), is used for this purpose. It is depicted in Fig. 2. The assumption in the SLM approach is that the ionosphere is a spherical thin shell layer with a fixed shell height above the surface of the earth. It is formulated as:

$m\left(E_{r}^{s}\right)=\frac{1}{\sqrt{1-\cos ^{2}(\beta)}}=\left[1-\frac{R_{E} \cos \left(E_{r}^{s}\right)}{R_{E}+h_{I}}\right]^{-1 / 2}$

with the radius of the earth, $R_{E}$, the ionospheric shell height, $h_{I}$, the elevation angle, $E_{r}^{s}$, and the complement of the incidence angle from satellite to the position of the receiver, $\beta$.

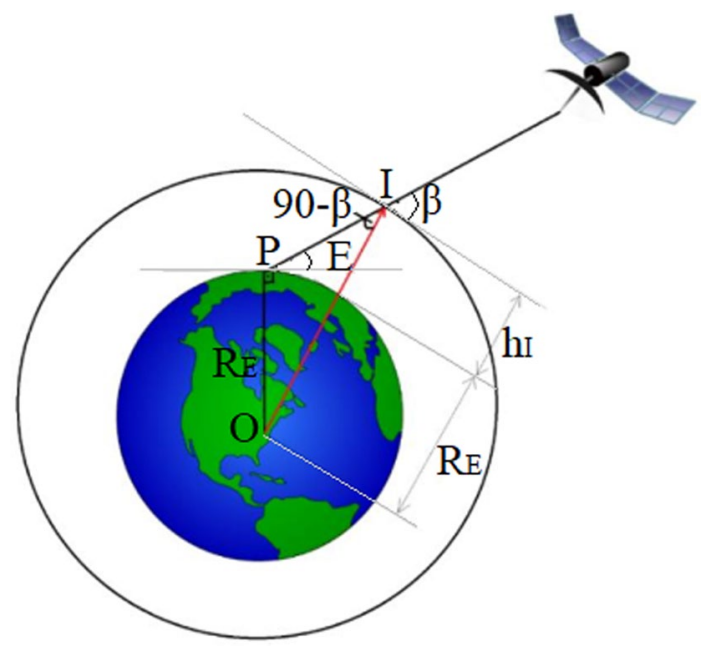

Fig. 2 Single layer model. $\mathrm{O}$ is the center of the earth, I is the ionospheric piercing point (IPP), and $\mathrm{P}$ is the position of the receiver

\section{DCB estimation analysis}

A flex power mode on a specific regional area has been activated on the L1 frequency for GPS Block IIF satellites since January 2017 (Steigenberger et al. 2018). Using the equations mentioned in the previous section, GPS DCBs are estimated using pseudorange observations on L1 and L2 frequencies between August 1 and November 21, 2019. First, DCB estimations are calculated without considering the flex power using a network, which is depicted in Fig. 1. DCBs are considered constant on a daily basis; therefore, each satellite has one constant DCB for each of the pseudorange observation combinations. Next, the estimations are done considering the flex power on Block IIF satellites. In this case, each GPS Block IIF satellite has two different DCBs for each of the pseudorange observation combinations, one for the time when the flex power is on and a second when it is off. The flex power is assumed active when the elevation of the Block IIF satellites from the position $41^{\circ} \mathrm{E} / 37^{\circ} \mathrm{N}$ is greater than $3^{\circ}$. It is important to note that the center point of the flex power and the elevation limit of $3^{\circ}$ are approximate assumptions of the location and the occurrence time of the flex power activation. The center point and elevation limit have been determined by fitting the resulting flex power activation area to simultaneously observed steps in the $\mathrm{C} /$ $\mathrm{N}_{0}$ measurements of several geodetic receivers, as depicted in Fig. 1. This simplified approach yields only approximate switching times, but it represents reality well enough for the purpose of DCB estimation.

The activation of the flex power can be seen from signalto-noise power density ratio measurements (Steigenberger et al. 2018). An exemplary day in the processed time period for an arbitrary IGS station is selected to depict the $\mathrm{C} / \mathrm{N}_{0}$ steps of three Block IIF satellites. Figure 3 shows the $\mathrm{C} / \mathrm{N}_{0}$ over time on September 26, 2019, for the Block IIF satellites G06, G10, and G09. On the right side of the figure, the elevation from the selected station is visualized. If the elevation is plotted in green, it means that the elevation of the satellite is greater than $3^{\circ}$ as seen from a ground-based location at $41^{\circ} \mathrm{E} / 37^{\circ} \mathrm{N}$. The elevation is shown in gray if it is smaller than $3^{\circ}$. In other words, in case the elevation is plotted in green, the satellite is inside of the flex power activation area. It should be noted that $\mathrm{S} 1 \mathrm{~W}$ is not shown in Fig. 3 as it is same as the $\mathrm{S} 2 \mathrm{~W}$ due to the semi-codeless tracking.

Figure 4 presents the averaged $\mathrm{C} 1 \mathrm{C}-\mathrm{C} 1 \mathrm{~W}$ intra-frequency DCB estimations throughout the estimated period of time for the cases with and without the flex power consideration in the estimation process. The green bar represents the case where the flex power is not considered in the estimation process. The red and the blue bars are for the case that the flex power is considered in the calculation. The red bar indicates the DCBs when the satellite is inside the flex power 
Fig. $3 \mathrm{C} / \mathrm{N}_{0}$ of $\mathrm{G} 06, \mathrm{G} 09$, and G10 signals and their elevations on September 26, 2019. G06 and G09 have been observed from the IGS station SUTH00ZAF and G10 has been tracked by VACSOOMUS. The elevations are plotted in green for the cases that the satellite is inside the flex power activation area and gray if it is outside
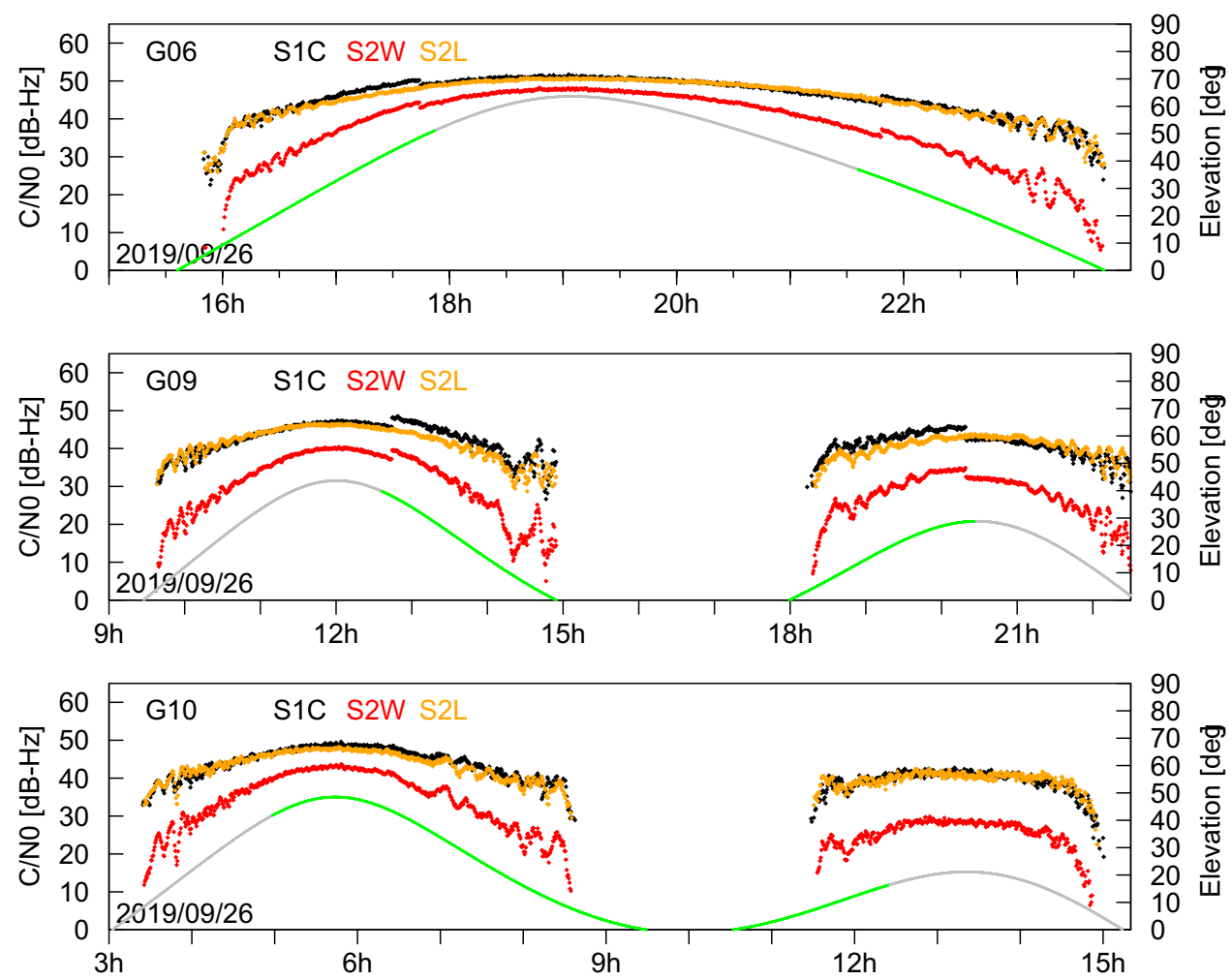

The $\mathrm{C} 1 \mathrm{C}-\mathrm{C} 1 \mathrm{~W}$ DCB estimation results in Fig. 4 are dif-
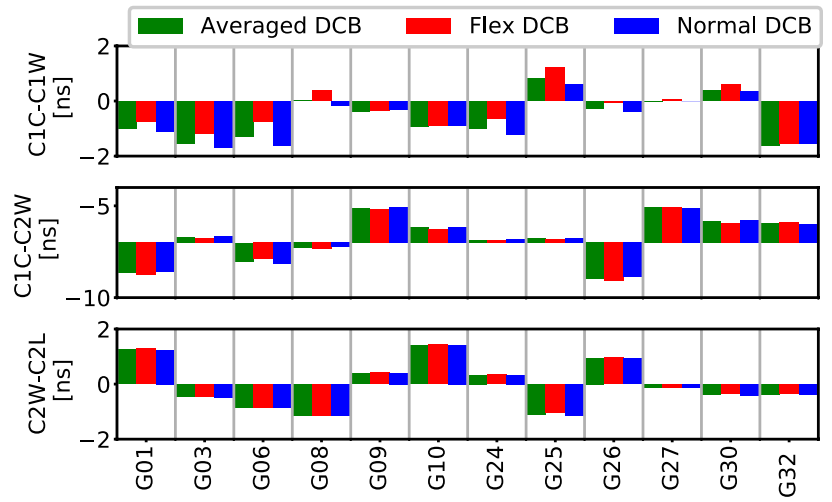

Fig. 4 Block IIF GPS DCB estimates with flex power consideration (blue and red) and without the flex power consideration (green). The center value of the middle plot is $-7 \mathrm{~ns}$

activation area and the blue bar when it outside. In other words, the green, red, and blue bars indicate the averaged DCBs, flex DCBs, and normal DCBs, respectively.

As it is clear from Fig. 4, the difference is more significant for the $\mathrm{C} 1 \mathrm{C}-\mathrm{C} 1 \mathrm{~W}$ DCB estimations. The details of this case are given in Table 2. Here, the mean of the $\mathrm{C} 1 \mathrm{C}-\mathrm{C} 1 \mathrm{~W}$ DCB estimates is given together with the standard deviation. In addition, the DCB difference between the flex and normal DCBs is calculated to see the impact of the flex power on the DCB estimations. ferent from each other for most of the Block IIF satellites. In Fig. 3, there is a significant jump for G06 on the signal-tonoise power-density ratio on S1C and S2W when the satellite is inside the flex power activation area approximately at 21:45 h, and outside approximately at 17:45 h. Hence, one can conclude that the flex power is switched on for the satellite G06. According to Table 2, the DCB changes by $0.87 \mathrm{~ns}$. This corresponds to approximately $1.6 \mathrm{TECU}$ on the L1 band.

The flex power is not switched on for all 12 Block IIF satellites. As it becomes obvious from Fig. 3, there is no significant jump for satellite G10 when the satellite enters the flex power activation area at 5:00 $\mathrm{h}$ and leaves it again at about 12:10 h. Therefore, there is no significant impact expected on considering the flex power in the calculations. Figure 4 and Table 2 confirm this expectation as the DCB difference is roughly a $0.01 \mathrm{~ns}$ or 0.02 TECU delay on the $\mathrm{L} 1$ band. This value also gives an indication of the precision of the DCB estimations.

It is also possible that the flex power is switched on without any significant impact on the DCB estimations. Figure 3 depicts a significant jump in the signal-to-noise powerdensity ratio on $\mathrm{C} 1 \mathrm{C}$ and $\mathrm{C} 2 \mathrm{~W}$ in the flex power active area, entering it at approximately $12: 45 \mathrm{~h}$, and leaving it at approximately 20:20 h. However, as it is shown in Fig. 4 and 
Table 2 Summary of the $\mathrm{C} 1 \mathrm{C}-$ C1W intra-frequency DCB estimation

\begin{tabular}{|c|c|c|c|c|c|}
\hline \multirow[t]{2}{*}{ Block IIF PRN } & \multirow[t]{2}{*}{ Block IIF SVN } & \multicolumn{3}{|c|}{ Estimated DCBs \pm standard deviation [ns] } & \multirow{2}{*}{$\begin{array}{l}\text { DCB difference } \pm \\
\text { standard deviation } \\
\text { [ns] }\end{array}$} \\
\hline & & Averaged DCBs & Normal DCBs & Flex DCBs & \\
\hline G01 & G063 & $-1.01 \pm 0.02$ & $-1.12 \pm 0.01$ & $-0.74 \pm 0.02$ & $0.38 \pm 0.01$ \\
\hline G03 & G069 & $-1.53 \pm 0.01$ & $-1.68 \pm 0.01$ & $-1.18 \pm 0.01$ & $0.50 \pm 0.01$ \\
\hline G06 & G067 & $-1.30 \pm 0.01$ & $-1.63 \pm 0.01$ & $-0.76 \pm 0.01$ & $0.86 \pm 0.01$ \\
\hline G08 & G072 & $0.02 \pm 0.01$ & $-0.17 \pm 0.01$ & $0.37 \pm 0.01$ & $0.54 \pm 0.01$ \\
\hline G09 & G068 & $-0.39 \pm 0.01$ & $-0.31 \pm 0.02$ & $-0.35 \pm 0.01$ & $-0.05 \pm 0.02$ \\
\hline G10 & G073 & $-0.94 \pm 0.01$ & $-0.89 \pm 0.01$ & $-0.89 \pm 0.01$ & $-0.01 \pm 0.01$ \\
\hline $\mathrm{G} 24$ & G065 & $-1.01 \pm 0.01$ & $-1.21 \pm 0.01$ & $-0.64 \pm 0.02$ & $0.56 \pm 0.01$ \\
\hline G25 & G062 & $0.81 \pm 0.03$ & $0.61 \pm 0.01$ & $1.22 \pm 0.07$ & $0.61 \pm 0.07$ \\
\hline G26 & G071 & $-0.29 \pm 0.02$ & $-0.39 \pm 0.02$ & $-0.04 \pm 0.03$ & $0.35 \pm 0.03$ \\
\hline G27 & G066 & $-0.03 \pm 0.01$ & $0.00 \pm 0.02$ & $0.06 \pm 0.01$ & $0.06 \pm 0.01$ \\
\hline G30 & G064 & $0.37 \pm 0.01$ & $0.33 \pm 0.01$ & $0.59 \pm 0.01$ & $0.25 \pm 0.01$ \\
\hline G32 & G070 & $-1.60 \pm 0.01$ & $-1.54 \pm 0.01$ & $-1.56 \pm 0.01$ & $-0.02 \pm 0.01$ \\
\hline
\end{tabular}

Table 2, this does not have a meaningful impact on the DCB estimates as the mean flex difference is $0.05 \mathrm{~ns}$.

The results also imply that in case the flex power is activated, the DCB estimates without flex power consideration are the weighted average of the two DCB estimates with flex power consideration. The standard deviations of the estimates are mostly $0.01 \mathrm{~ns}$, which indicate the precision of the DCB estimations. However, the standard deviation of the DCB difference of the G25 Block IIF is seven times higher. Therefore, daily DCB estimates for G25 are shown in Fig. 6. As before, the green, red, and blue lines indicate the averaged DCBs, flex DCBs, and normal DCBs, respectively.

Figures 5, 6 show that the flex power is not activated for G25 on September 26, 2019. In Fig. 6, the averaged, normal, and flex power DCB estimation results for satellite $\mathrm{G} 25$ are identical within the expected error range on September 26. Figure 5 depicts the $\mathrm{C} / \mathrm{N}_{0}$ on September 26 and the day before. On September 26, when all DCB estimates agree with each other, there is no drop or jump in the $\mathrm{C} / \mathrm{N}_{0}$. However, a significant drop occurs on the signal-to-noise-power-density ratio when the satellite is outside the flex activation area approximately at 6:30 h. Hence, the flex power for the satellite G25 was not active on September 26.

In addition, it should also be mentioned that the estimations of $\mathrm{C} 1 \mathrm{C}-\mathrm{C} 1 \mathrm{~W}$ DCB also agree with the high rate C1C-C1W DCB estimation with spacing of 15 min provided by Steigenberger et al. (2018) that was estimated on the first 4 days of June 2018. Although this period is roughly a year earlier with respect to the analyzed period of time, as satellite DCBs are quite stable, this agreement is expected.

It can be summarized that the flex power is switched on for most of the Block IIF satellites except G10 and G32. Satellites G09 and G27 are exceptional in this case as their DCBs are not significantly affected by the flex power activation. In addition, the flex power cannot be activated on an arbitrary day, while it was activated before. This can be seen in the G25 Block IIF satellite on September 26, when the flex power is not switched on for this day.

Furthermore, Fig. 4 also shows that the impact of the flex power consideration in the DCB estimation process is significant for $\mathrm{C} 1 \mathrm{C}-\mathrm{C} 1 \mathrm{~W}$ intra-frequency estimations. For the satellites with flex power activated, the flex power affects the $\mathrm{C} 1 \mathrm{C}-\mathrm{C} 1 \mathrm{~W}$ DCB estimations by roughly $0.4 \mathrm{~ns}$ on average. However, this is not the case for the $\mathrm{C} 1 \mathrm{C}-\mathrm{C} 2 \mathrm{~W}$ inter-frequency and $\mathrm{C} 2 \mathrm{~W}-\mathrm{C} 2 \mathrm{~L}$ intra-frequency DCB estimations. For $\mathrm{C} 1 \mathrm{C}-\mathrm{C} 2 \mathrm{~W}$, the impact of the flex power is approximately $0.1 \mathrm{~ns}$, which is below the accuracy of the final ionospheric TEC grid product provided by IGS. Therefore, the impact of the flex power estimations

Table 3 Summary of the L1/L2 inter-frequency and L2 intra-frequency DCB estimations

\begin{tabular}{llrl}
\hline Block IIF PRN & Block IIF SVN & \multicolumn{2}{c}{$\begin{array}{l}\text { DCB difference } \pm \text { standard } \\
\text { deviation }[\mathrm{ns}]\end{array}$} \\
\cline { 3 - 4 } & & C1C-C2W & C1C-C2W \\
\hline G01 & G063 & $-0.17 \pm 0.06$ & $0.05 \pm 0.02$ \\
G03 & G069 & $-0.10 \pm 0.07$ & $0.04 \pm 0.02$ \\
G06 & G067 & $0.25 \pm 0.06$ & $0.03 \pm 0.02$ \\
G08 & G072 & $-0.09 \pm 0.09$ & $0.01 \pm 0.01$ \\
G09 & G068 & $-0.11 \pm 0.07$ & $0.01 \pm 0.02$ \\
G10 & G073 & $-0.09 \pm 0.06$ & $0.02 \pm 0.02$ \\
G24 & G065 & $-0.07 \pm 0.08$ & $0.04 \pm 0.01$ \\
G25 & G062 & $-0.04 \pm 0.06$ & $0.12 \pm 0.03$ \\
G26 & G071 & $-0.19 \pm 0.05$ & $0.02 \pm 0.02$ \\
G27 & G066 & $0.02 \pm 0.07$ & $0.01 \pm 0.02$ \\
G30 & G064 & $-0.14 \pm 0.06$ & $0.04 \pm 0.01$ \\
G32 & G070 & $0.06 \pm 0.05$ & $0.02 \pm 0.02$ \\
\hline
\end{tabular}


Fig. $5 \mathrm{C} / \mathrm{N}_{0}$ of $\mathrm{G} 25$ signals and its elevation on September 25 and 26, 2019, from station ABPO00MDG. The elevations are marked green for the cases that the elevation is larger than $3^{\circ}$ at $41^{\circ} \mathrm{E} / 37^{\circ} \mathrm{N}$ and gray if it is lower
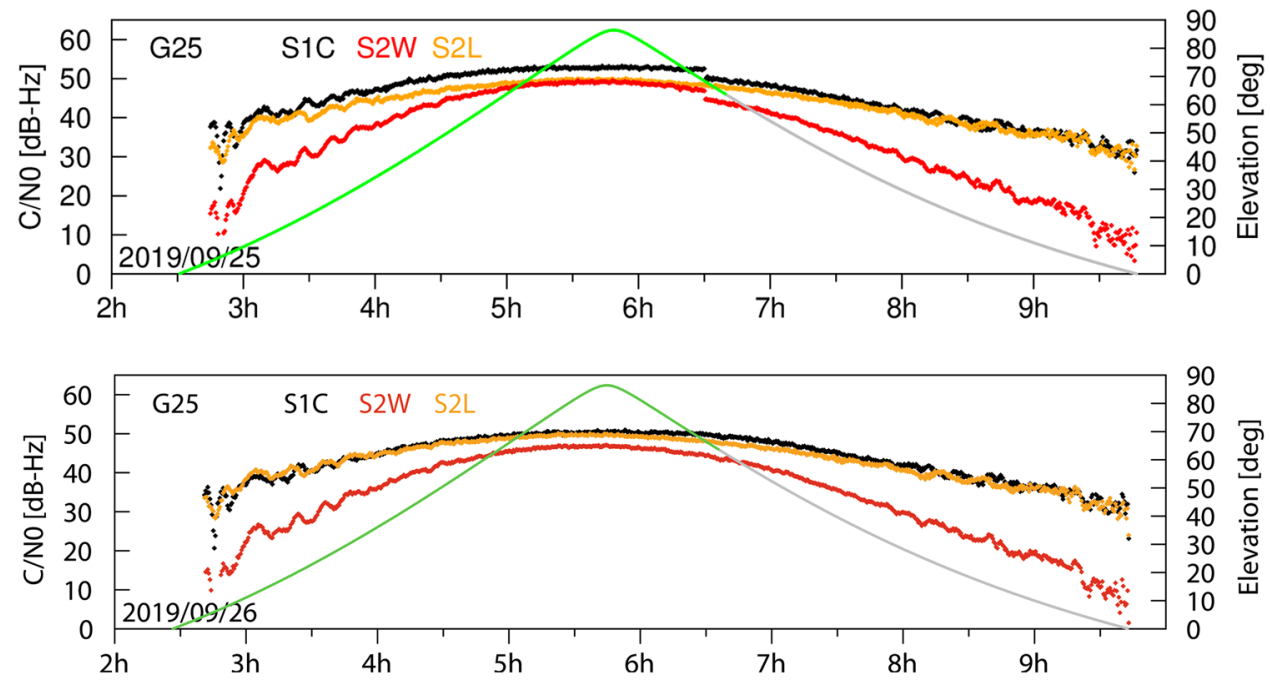

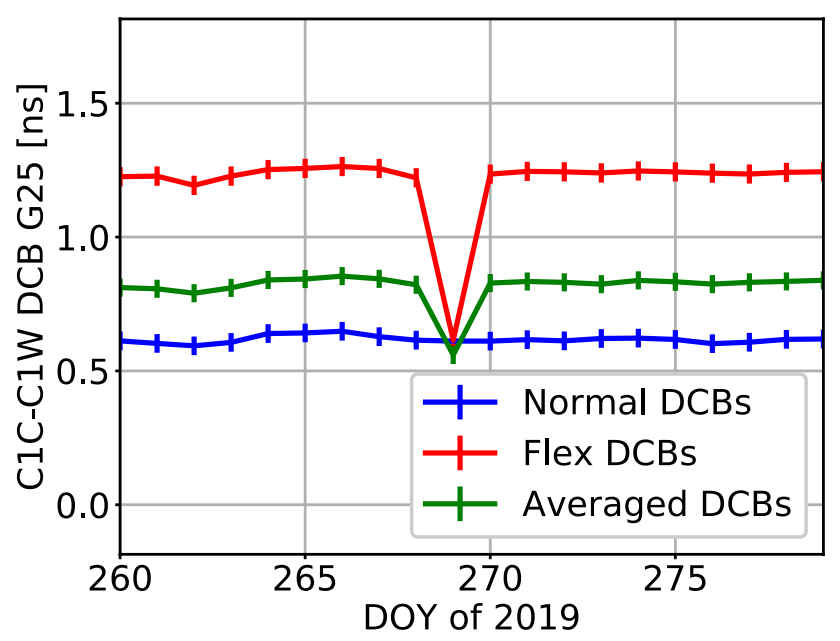

Fig. 6 G25 C1C-C1W DCB estimates for separate flex power estimation (blue and red) as well as for combined DCB estimation (green). The standard deviations of each estimate are shown as error bars for $\mathrm{C} 1 \mathrm{C}-\mathrm{C} 2 \mathrm{~W}$ is absorbed by the ionospheric corrections. Additionally, it should be noted that the standard deviation is higher than intra-frequency DCB estimates due to the effect of the ionosphere. The impact of the flex power on $\mathrm{C} 2 \mathrm{~W}-\mathrm{C} 2 \mathrm{~L}$ is approximately $0.03 \mathrm{~ns}$ for all Block IIF satellites (Table 3).

\section{Inter-agency DCB comparison}

The estimated DCBs are compared with the German Aerospace Center (DLR) as well as the Chinese Academy of Sciences (CAS). These agencies provide DCB products as a part of the IGS Multi-GNSS Experiment (MGEX) (Wang et al. 2016). The DLR DCB products are provided on a 3-month basis and it contains daily as well as weekly averaged DCBs. For this comparison, daily DLR products are used. CAS DCB products are provided with 2-3 days of
Fig. 7 DCB comparison with CAS (red) and DLR (blue). The stars indicate the comparison with normal DCBs, which does not include flex power. The diamonds represent the comparison with averaged DCBs when the flex power is not considered in the estimation

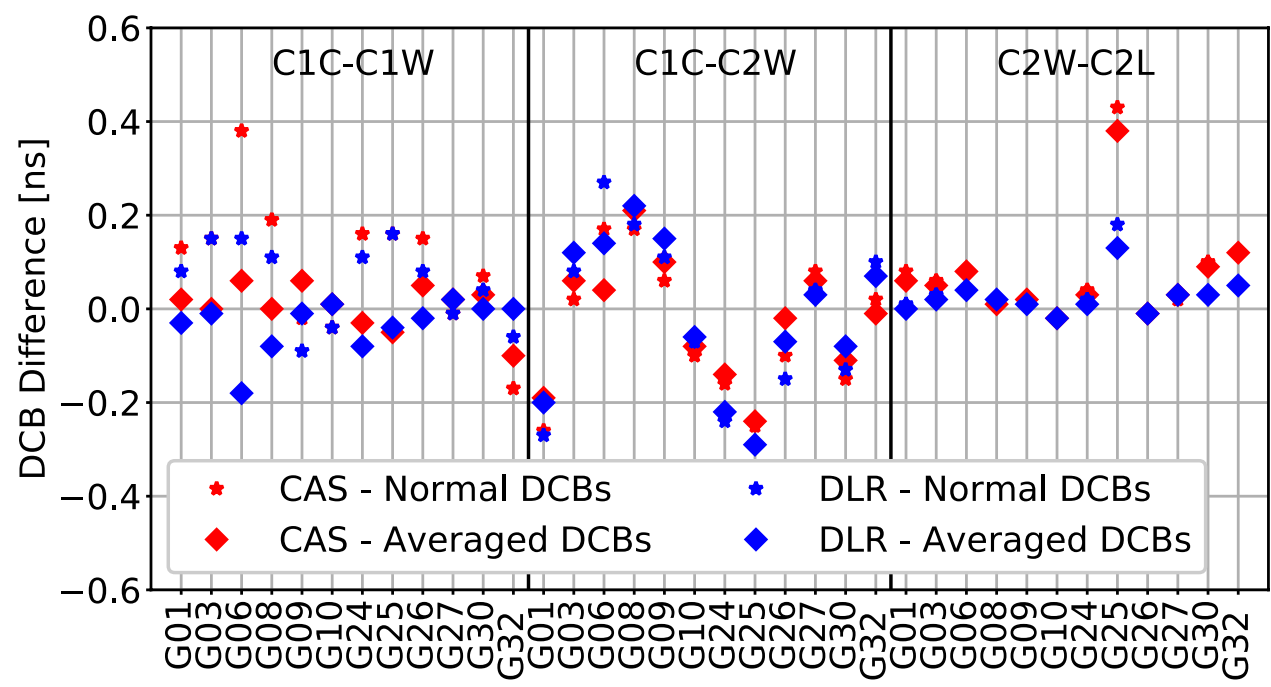


Table 4 Standard deviation of CAS comparison and DCB estimation with and without flex power consideration

\begin{tabular}{lll}
\hline Standard deviation [ns] & $\begin{array}{l}\text { CAS DCBs-aver- } \\
\text { aged DCBs }\end{array}$ & $\begin{array}{l}\text { CAS DCBs- } \\
\text { normal DCBs }\end{array}$ \\
\hline C1C-C1W & 0.05 & 0.14 \\
C1C-C2W & 0.12 & 0.14 \\
C2W-C2L & 0.10 & 0.11 \\
\hline
\end{tabular}

Table 5 Standard deviation of DLR comparison and DCB estimation with and without flex power consideration

\begin{tabular}{lll}
\hline Standard deviation [ns] & $\begin{array}{l}\text { DLR DCBs-Aver- } \\
\text { aged DCBs }\end{array}$ & $\begin{array}{l}\text { DLR DCBs- } \\
\text { Normal DCBs }\end{array}$ \\
\hline C1C-C1W & 0.05 & 0.08 \\
C1C-C2W & 0.16 & 0.18 \\
C2W-C2L & 0.04 & 0.05 \\
\hline
\end{tabular}

latency by the Institute of Geodesy and Geophysics (IGG) in Wuhan (Wang et al. 2016). The results are compared for the cases with and without the flex power consideration.

Figure 7 shows the averaged DCB estimations with or without the flex power consideration in the afore-mentioned network with the CAS as well as DLR results. The standard deviation of this comparison is given in Table 4. Since the CAS products do not consider the flex power in the calculation of DCBs, the standard deviation of the case with flex power consideration has a higher standard deviation. Particularly, the standard deviation of $\mathrm{C} 1 \mathrm{C}-\mathrm{C} 1 \mathrm{~W}$ intra-frequency DCBs is approximately twice as large as for the flex power considered estimation.

The standard deviation of the comparison to DLR DCBs is given in Table 5. Similar to the CAS products, the DLR products also do not consider the flex power in the calculation of DCBs. Therefore, lower standard deviations are expected for the case without flex power consideration.

Both comparisons are made for validating the estimation results of this paper. As both products do not consider the flex power in the estimations, differences occur in the normal DCB comparisons. The standard deviations of the averaged DCBs' comparisons are lower. This was expected as neither of the estimations considers the flex power in the calculations. However, differences still occur as both products use a network of different receivers including different flavors of receiver types, whereas ours only covers one receiver type.

\section{Summary and conclusion}

The flex power has been activated over a specific regional area for GPS Block IIF satellites (Steigenberger et al. 2018). The impact of these power changes is visible on the measured $\mathrm{C} / \mathrm{N}_{0}$ and DCB estimations. To analyze this impact, the DCBs are estimated with and without flex power considerations between August 1 and November 21, 2019. A network of PolaRx5 and PolaRx5TR receivers is used to decrease the impact of other effects caused by the receiver differences. Flex power has an impact on most of the Block IIF satellites. This impact is approximately $0.4 \mathrm{~ns}$ on $\mathrm{L} 1 \mathrm{C} 1 \mathrm{C}-\mathrm{C} 1 \mathrm{~W}$ intra-frequency DCB estimations, $0.1 \mathrm{~ns}$ on $\mathrm{L} 1 / \mathrm{L} 2 \mathrm{C} 1 \mathrm{C}-\mathrm{C} 2 \mathrm{~W}$ inter-frequency $\mathrm{DCB}$, and $0.03 \mathrm{~ns}$ for L2 C2W-C2L intra-frequency DCBs. The consideration of the flex power is significant particularly for $\mathrm{C} 1 \mathrm{C}-\mathrm{C} 1 \mathrm{~W}$ DCB estimations. The impact of flex power is less pronounced on the inter-frequency DCB estimates for two reasons. First, there is no flex power active on the L2 signal. Second, the inter-frequency DCBs require simultaneous estimation of the ionospheric delay, which may partially compensate the DCB change. It also increases the noise in the resulting DCB, which makes the change due to flex power less well distinguishable. The precision of the DCB estimates is assumed to be on the order of a few hundreds of nano-seconds which has been confirmed with Block IIF satellites, for which flex power is not activated. In addition, the DCB estimations are compared with DLR and CAS for validation purposes. It has been seen that the standard deviation of this comparison is higher when the flex power is considered in the estimation process. This is because both of these products do not consider the flex power into the calculations.

Acknowledgements Open Access funding provided by Projekt DEAL.

Data availability Data supporting this research are obtained from (Johnson et al. 2018) as well as the archive of space geodesy data of National Aeronautics and Space Administration (NASA) (Noll 2010).

Open Access This article is licensed under a Creative Commons Attribution 4.0 International License, which permits use, sharing, adaptation, distribution and reproduction in any medium or format, as long as you give appropriate credit to the original author(s) and the source, provide a link to the Creative Commons licence, and indicate if changes were made. The images or other third party material in this article are included in the article's Creative Commons licence, unless indicated otherwise in a credit line to the material. If material is not included in the article's Creative Commons licence and your intended use is not permitted by statutory regulation or exceeds the permitted use, you will need to obtain permission directly from the copyright holder. To view a copy of this licence, visit http://creativecommons.org/licenses/by/4.0/. 


\section{References}

Federal Radionavigation Plan (2019). https://www.navcen.uscg.gov/ pdf/FederalRadioNavigationPlan2019.pdf

Fisher SC, Ghassemi K (1999) GPS IIF-The next generation. Proc IEEE 87(1):24-47. https://doi.org/10.1109/5.736340

Geng J, Teferle N, Meng X, Dodson A (2011) Towards PPP-RTK: ambiguity resolution in real-time precise point positioning. Adv Space Res 47(10):1664-1673. https://doi.org/10.1016/j. asr.2010.03.030

Hauschild A (2017) Basic observation equations. In: Teunissen PJG, Montenbruck O (eds) Springer handbook of global navigation satellite systems. Springer Handbooks. Springer, Cham, pp 566-567. https://doi.org/10.1007/978-3-319-42928-1_19

Hauschild A, Montenbruck O (2016) A study on the dependency of GNSS pseudorange biases on correlator spacing. GPS Solut 20(2):159-171. https://doi.org/10.1007/s10291-014-0426-0

IGS RINEX WG, RTCM-SC104 (2018) RINEX: The receiver-independent exchange format Version 3.04. ftp://igs.org/pub/data/ format/rinex304.pdf

IS-GPS-200 K (2019) NAVSTAR GPS space segment/navigation user segment interfaces. https://www.gps.gov/technical/icwg/IS-GPS200K.pdf

Johnston G, Riddell A, Hausler G (2017) The International GNSS Service. In: Teunissen PJG, Montenbruck O (eds) Springer handbook of global navigation satellite systems, Springer Handbooks. Springer, Cham, pp 967-982. https://doi.org/10.1007/978-3-31942928-1_33

Montenbruck O, Hauschild A, Steigenberger P (2014) Differential Code Bias Estimation using Multi-GNSS Observations and Global Ionosphere Maps. Navigation 61(3):191-201. https://doi. org/10.1002/navi.64

Noll C (2010) The crustal dynamics data information system: a resource to support scientific analysis using space geodesy. Adv Space Res 45(12):1421-1440. https://doi.org/10.1016/j. asr.2010.01.018

Rajan JA, Tracy JA (2002) GPS IIR-M: Modernizing the Signal-inSpace. In Proc. ION GPS 2002, Institute of Navigation, Portland, Oregon, USA, September 24-27, pp 1585-1594

Sardón E, Zarraoa N (1997) Estimation of total electron content using GPS data: how stable are the differential satellite and receiver instrumental biases? Radio Science 32(5):1899-1910. https://doi. org/10.1029/97RS01457

Steigenberger P, Thölert S, Montenbruck O (2018) Flex power on GPS Block IIR-M and IIF. GPS Solut 23(1):8. https://doi.org/10.1007/ s10291-018-0797-8

Wang N, Yuan Y, Li Z, Montenbruck O, Tan B (2016) Determination of differential code biases with multi-GNSS. J Geodesy 90(3):209-228. https://doi.org/10.1007/s00190-015-0867-4
Publisher's Note Springer Nature remains neutral with regard to jurisdictional claims in published maps and institutional affiliations.

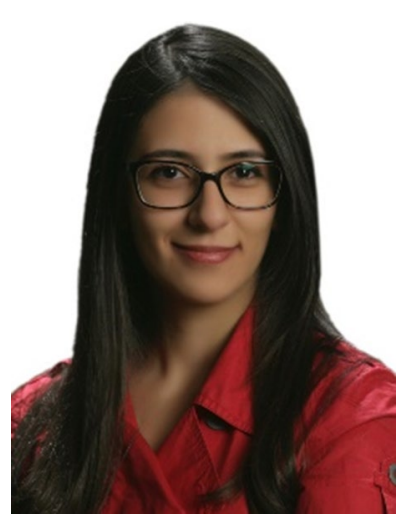

Özge Gizem Esenbuğa received her B.S. degree in geomatics engineering from Istanbul Technical University in 2016, and an M.S. degree in earth oriented space science and technology (ESPACE) from Technical University of Munich in 2018. Right after her graduation, she joined the German Space Operations Center (GSOC) at DLR. Her research interest is on GNSS data analysis, in particular differential code bias determination of GNSS satellites and ionosphere modeling. She also works on projects with interface development for GNSS data visualization.

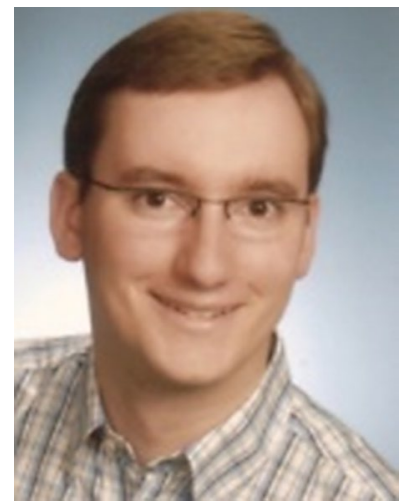

André Hauschild is a scientific staff member at DLR's German Space Operations Center (GSOC). His work focuses on precise real-time clock estimation for GNSS satellites and multi-GNSS processing using new and modernized satellite navigation systems. André is also involved in projects with space-borne GNSS for scientific applications on satellites and rockets. Since 2014, he is a member of Eumetsat's Radio Occultation Science Advisory Group and he leads the International GNSS Service (IGS) real-time working group since 2019. He is the 2019 recipient of the Institute of Navigation's Tycho Brahe Award. 